\title{
CONHECIMENTOS NO COTIDIANO: SITUAÇÕES E ESTÓRIAS
}

\author{
Elizabeth B. Silva \\ Sociology, The Open University
}

ABSTRACT The author discusses antecedents and consequences of the construction of our knowledge categories for scientific practice and daily life. She argues that methodological and scientific criteria are not the only basis for electing what and what not matters in scientific knowledge. As an example of this, she analyses the existent tension between quantitive and qualitative methodologies as conventional techniques to obtain knowledge.

KEY WORDS Categories. Common life. Knowledge. Quantitive and qualitative methodologies.

RESUMEN La autora discute los antecedentes y consecuencias que tienen la construcción de nuestras categorías de conocimiento en la vida cotidiana y en la práctica científica. Mantiene que la elección de lo que es importante en el campo del conocimiento no es el resultado sólo de criterios metodológicos y científicos. Para mostrarlo, examina la tensión existente entre la metodologia cuantitativa y la cualitativa como metodologías convencionales para obtener conocimiento.

PALABRAS CLAVE Categorías. Vida cotidiana. Conocimiento. Metodologias cuantitativa y cualitativa.

\section{Introdução}

\begin{tabular}{|c|c|c|}
\hline \multirow{2}{*}{ Tecnologia } & Cotidiano & Conhecimento \\
\hline & Gênero & \\
\hline Ciência & Futuro & Sociedade \\
\hline eroAmérica & América Latina & Propostas \\
\hline
\end{tabular}

Este texto tem origem numa palestra que fiz no Brasil em mesa redonda sobre "Ciência, Tecnologia e Gênero na lberoAmérica: problemas e propostas?". ${ }^{1}$ Procurando um engajamento especifico com o tema, uma série de palavras saltou aos meus olhos:

É claro que todas estas palavras estão cheias de significados. E quais eram eles para mim? Eu agrupei as palavras em conjuntos de significados e dei rótulos aos conjuntos:

\begin{tabular}{|lccc|}
\hline \multicolumn{1}{|c|}{} & & \\
\hline Maneira & Localização & Localidade & Porque \\
\hline do conhecer & do conhecer & do conhecer & do conhecer \\
& & & \\
Ciência & Gênero & lberoAmérica & Problemas \\
$\begin{array}{l}\text { Conhecimento Cotidiano } \\
\text { Tecnologia }\end{array}$ & Sociedade & América Latina & Propostas \\
\hline
\end{tabular}

É muito possivel que a leitora não concorde com o meu agru- hecer?» Pode ser que o leitor esteja curioso sobre os rumos pamento ou com os meus rótulos, e que neste momento do meu argumento, ou que esteja fazendo qualquer outra esteja pensado: "Mas, porque colocar gênero como "locali- inquisição, como por exemplo: "Qual é o ponto deste exercização»? Ou como pode tecnologia ser uma «maneira" do con- cio?» A minha intenção é discutir as necessidades e as impli- 
cações das construções de categorias para o conhecimento, e as relações que 0 ato de classificar tem com 0 ato de conhecer, tanto no cotidiano, quanto na pratica cientifica.

Neste artigo eu discuto estas questões em tres sessoes. Eu inicio pela tensão corrente sobre o que constitui a melhor maneira de fazer ciência, invocando, a grosso modo, debates sobre duas formas convencionais de metodologia científica: quantitativa e qualitativa. Eu discuto a seguir as implicações dos "conhecimentos situacionados", assim como apresentado por Haraway (1988), e amplio esta discussao para o contexto latinoamericano. Na terceira sessao, eu endereco certas reflexões sobre "estórias do cotidiano e as maneiras de conhecer", centrando-me na vida de dia a dia das mulheres. Meu argumento é que a seleção do que é importante no campo do conhecimento nao deriva exclusivamente de livre escolha de opinião, ou de critérios metodológicos e científicos. Escolhas e direções científicas estão inseridas em contextos coletivos e gerais complexos que dependem significativamente de posições individuais no cotidiano. Todavia, ao ressaltar a forca do individual e do particular no coletivo, eu não deixo de perceber o outro lado da moeda: as limitações do individual no geral e coletivo. Para isto, eu chamo a atenção para o entendimento da relevancia de políticas cotidianas que fortalecam a agência das minorias e dos individuos. Minha preocupacao cnetral e com a vida cotidiana das mulheres e com as politicas e epistemologias feministas.

\section{Tensões do conhecer}

No inicio do século vinte e um eu acho muito difícil compreender a existência de concepções de ciência com objetivos de "neutralidade de valores" em busca de "verdades universais e objetivas" sobre natureza (e corpos) e matéria (e tecnologia). Felizmente eu penso num mundo onde estas idéias sao constantemente desafiadas ${ }^{2}$. Meus estudos se inserem na area de ciência e tecnologia no campo sóciocultural, onde se assumem que existem fatores culturais, psicologicos, políticos e sociais que dao forma ao conhecimento cientifico. Eu também, felizmente, vivo num mundo onde se assume que as ideologias de gênero afetam o conhecimento. Mas é claro que existem tensoes em todos estes aspectos do que é que afeta o conhecer: valores, culturas, sociedades, e condicoes materiais, entre outros. Por exemplo, a mudanca no balanco de gênero numa comunidade cientifica especifica não é suficiente para afetar a ideologia de gênero, porque ter mais mulheres trabalhando num mesmo lugar, ou sobre um assunto em comum, não leva automaticamente ao entendimento de como as ideologias de gênero afetam a ciência. Até uma renomada cientista como Evelyn Fox Keller (1992) comenta que foi dificil para ela entender como a subjetividade de gênero podia afetar a ciência. Claramente isto nao se refere exclusivamente a mulheres: e importante relembrar que homem também tem gênero. Numa reflexao paralela e pertinente, é importante tambem ressaltar que "branco" tambem é raca. Todavia, muitas vezes o masculino é tido como genero universal e o branco é invisibilizado na problematica racial. A percepção de como os nossos (as vezes «invisiveis») valores, crencas e ideologias afetam o conhecimento cientifico -ou as maneiras de classificar- implica num desafio radical nas maneiras de fazer ciência.

Ann Oakley argumenta num livro recente (2000) que representações ideologicas de gênero encontram-se embutidas nas metodologias "quantitativas" e "qualitativas». Apesar de estudos qualitativos existirem na disciplina de sociologia desde a década de 1920, a "guerra" dos paradigmas foi enormemente energizada com o movimento feminista do final da decada de 1960. 0 movimento feminista surgiu como um movimento social, alcancou e se difundiu na academia e veio a dizer muito sobre metodologia. Os primeiros textos feministas em ciências sociais apareceram no inicio da decada de 1970. Nos estudos de ciência e tecnologia, o feminismo comecou a marcar as discussoes cerca de uma decada mais tarde. Um aspecto central dos estudos iniciais era a discussao da dominação dos homens na academia. Este era um assunto quantitativo: haviam e ainda ha, muito mais homens em posições de mando, em postos de senioridade na academia. Por exemplo, na conferencia na qual eu apresentei as ideias iniciais deste artigo, haviam 6 mesas redondas, 3 delas tinham apenas homens, 2 mesas redondas tinham uma mulher em cada uma, e outra mesa redonda, sobre genero, tinha 4 mulheres. Ao todo, havia 19 conferencistas nas 6 mesas redondas, entre estes, 6 eram mulheres (menos de 1/3). Mas a distribuicao de genero, com participacao diminuta de mulheres, tambem era no inicio da decada de 1970 um assunto qualitativo, uma questao de perspectiva: como e que os homens davam -e dao- forma ao conteudo das materias academicas e as maneiras de conhecer? Como ilustracao, na conferencia que tomo como exemplo, a discussao de genero aparecia isolada dos demais temas e competindo em horario e interesse com outra discussao prominente. $E$ isto aconteceu na progressista Uni- 
versidade de Campinas, no sul do Brasil, ja no seculo vinte e um. Nos estudos academicos feministas iniciais ressaltava-se que as experiencias e as vozes da mulheres estavam ausentes, ou eram diminuidas, ou vistas como inapropriadas, ou eram distorcidas. Argumentos contra o "quantitativo" eram acompanhados pela celebração da alternativa "qualitativan. Este dualismo, todavia, designava processos culturais profundos, indo muito alem de uma questao sobre metodologias cientificas.
A tabela 1 apresenta o conteudo basico desse dualismo. Em termos de abordagem de pesquisa e de posição da pesquisadora, ou do pesquisador, os metodos podem ser sintetizados assim: Pensemos na ideia de que existe um mundo para ser conhecido. Isto implica na ideia do conhecedor. 0 conhecedor e 0 "expert», 0 conhecido e o objeto do conhecimento de alguem, ao inves de ser objeto do seu proprio conhecimento. E neste contexto que entra a questao do poder. 0 conhecimento especializado (do «expert») significa uma hierarquia de relações de poder.

TABELA 1: A «Guerra» dos Paradigmas

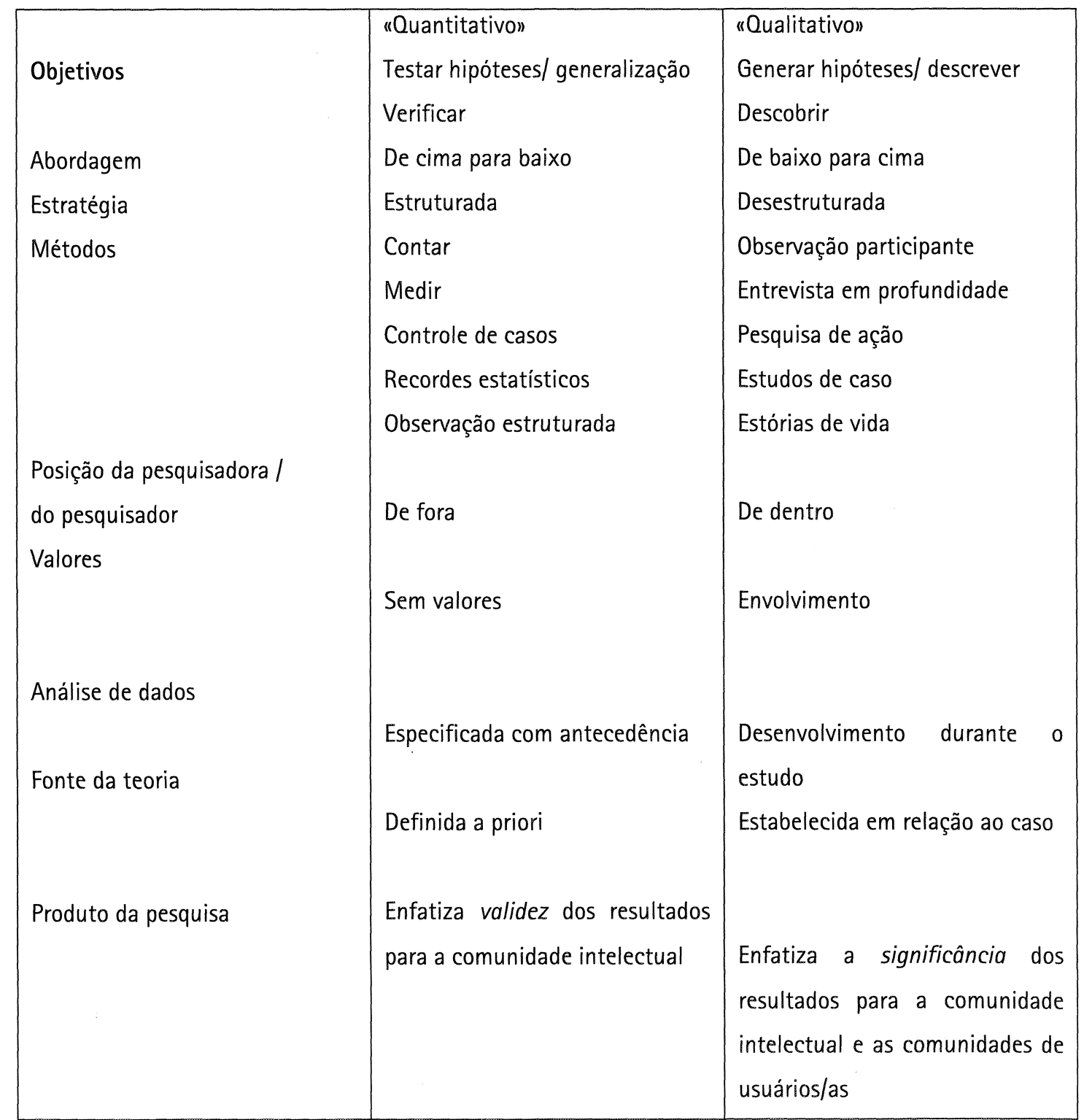


Como e que esta posição do conhecedor separado do "objeto» de conhecimento difere de posições feministas?

Posicoes feministas divergem sobre uma serie de questoes, mas e possivel se afirmar que feminismo e democratico. Existe em feminismo uma noção implicita de obrigação moral de tratar os outros como se gostaria de ser tratada. Mas ai existe um problema. Existe sempre uma relação de poder entre a pesquisadora e participantes. (Eu quero fazer notar que eu falo de participantes, não de "sujeitos».) 0 enfrentamento desta questao do poder na relação de pesquisa e fundamental. Oakley (2000), por exemplo, assume que a guerra entre os paradigmas e não mais do que uma outra forma de guerra entre os sexos. A dicotomia funciona como "descrições de gênero de maneiras de conhecer". Ela argumenta, e eu concordo, que em realidade, pesquisadoras "qualitativas" fazem consideravel uso de quantificação e, por exemplo, usam expressões como "a maioria", "todos", "algumas", "frequentemente" e por ai afora. A oposição não e sobre praticas reais de pesquisa. A oposição e sobre teorias do que e o conhecimento.

Assim, o metodo "quantitativo" permanece sendo a tradição mais forte e e menos frequente ver-se pesquisadores nesta tradição defenderem o que fazem. Entao, porque e que o paradigma "qualitativo" tem mais problemas em se fazer ouvir? Por um lado, isto advem da estoria da re-emergencia dos estudos "qualitativos» ligados a questoes de gênero dentro do movimento feminista, como eu me referi acima. Por outro lado, isto tambem advem de um processo de fragmentação das teorias totalizadoras que fizeram parte do projeto de modernidade. E e claro que o feminismo e um elemento crucial desta fragmentação teorica corrente.

Bruno Latour (1994) menciona o processo de purificação almejado pelo processo de modernização - a criação de categorias "puras" dualistas de humano/não-humano, sociocultural/natureza, dentro de um mundo baguncado, numa realidade cheia de formas hibridas. Ele argumenta que em verdade, o hibrido e a norma: não existem objetos naturais puros, sujeitos humanos puros ou relações sociais puras. Entao uma politica de identidade "pura» não e possivel. Exis- te uma infinidade de agentes que não se encaixam nas categoria puras descritas para elas, ou para eles. A mulher do terceiro mundo, por exemplo, compreende varios tipos de mulheres: negra, branca, educada, rica, pobre, prostituta, solteira, favelada, mae, empregada domestica, executiva, etc.

$\mathrm{Na}$ atividade de pesquisadora, como se pode dar conta dos pontos de vista diferentes? Como se pode expressar os pontos de vistas dos varios pesquisadores e dos varios grupos, ou pessoas, participantes na pesquisa? Como se pode compreender, relatar e refletir sobre os interesses diversos em relação aos resultados das empreitadas cientificas?

Uma maneira de dar conta disto refere-se a questao dos conhecimentos situacionados.

\section{Conhecimentos situacionados: implicacoes gerais}

A noção de conhecimentos situacionados, conforme Haraway (1988) se relaciona com o corpo. 0 "olhar cientificon e afinado com a ideia de que se ve sempre de algum lugar. Sempre se ve sob um certo ponto de vista, o qual e baseado no corpo, na historia e na cultura. 0 mundo nasce atraves do processo de se ir vendo. E claro que não se ve apenas com os olhos. Como se pode aprender a ver fielmente do ponto de vista do outro, da outra?

0 pensamento de Donna Haraway e relevante neste contexto. Ela diz que a visao e sempre uma questao do poder de ver. E que a otica e uma politica de posicionamento. Voce ve de uma certa otica. Não e possivel portanto estabelecer uma posição total, completa. Isto significa que a unica maneira de alcancar uma visao mais abrangente e a partir de se estar num lugar em particular. Deste lugar particular a visao e parcial. E entao do conjunto de conhecimentos parciais, que sao problematicos, contingentes e inacabados, que se pode visualizar uma perspectiva privilegiada de conhecimento.

$\mathrm{Na}$ tabela 2 eu apresento a sintese destas ideias, para esclarecer este argumento. 
TABelA 2: Sintese de "Conhecimento Situacionado" cf. Donna Haraway

\begin{tabular}{|l|l|l|}
\hline Totalização & Relativismo & Conhecimentos situacionados \\
Visao singular & "estar em lugar nenhum e & Localizaveis \\
Não-marcada & assumir que se esta igualmente & Criticos \\
Obscurecimento & em todo lugar». - "lgualdade»: & En-corporados [0 corpo e um \\
& negação de responsabilidade e de & agente, não um recurso] \\
& investigação critica & \\
\hline
\end{tabular}

Uma visao a partir do corpo
e diferente de
uma visao a partir de lugar nenhum

0 argumento em favor dos conhecimentos situacionados tem sido refinado nos mais de 10 anos em que este vem sendo discutido. Eu estou exemplificando com Donna Haraway porque foi ela quem cunhou esta expressao. Mas o proprio desenvolvimento do pensamento de Haraway se assenta dentro de um movimento mais abrangente de epistemologias feministas. Notem que eu estou usando plurais para me referir a estas concepções. Não ha uma visao unica. Parece que o consenso prevalecente e que os metodos de se fazer ciência podem ser varios. A questao fundamental em ciencia e se a pesquisa e feita conforme criterios abertos e sistematicos que podem ser inspecionados por outras pessoas. E claro que isto implica em acabar com o androcentrismo, enquanto se faz inquisições sistematicas.

Concretamente, quais as implicações dos conhecimentos situacionados? Como se faz para trabalhar dentro deste tipo de proposta de conhecimento?

\section{Estórias do cotidiano e maneiras de conhecer}

Nos estamos tratando de conhecimentos com localização historica determinada. Nos estamos assumindo que a situação social de quem conhece apresenta limites sobre o que e possivel conhecer. Nos entendemos que as formas de classificar dependem da posicao do classificador. A epistemologia feminista argumenta -e existe consenso sobre isto- que a situação social do dominante e mais limitadora para o conhecimento porque ela não gera as questoes criticas sobre crencas recebidas (Harding, 1996).

Vejamos que, por exemplo, Dorothy Smith $(1988,1990)$ argumenta que a experiencia das mulheres e 0 terreno donde se perguntar sobre a vida das mulheres, a vida dos homens e as relações de causalidade entre as vidas das mulheres e dos homens. Por que?

Porque e atribuido as mulheres o trabalho de cuidar dos corpos: dos homens, dos bebes, das criancas, dos idosos, dos doentes, de si mesmas. E Ihes e atribuido responsabilidade pelos locais onde estes corpos existem, uma vez que sao elas quem limpam e cuidam de suas casas, das casas de outros e dos locais de trabalho. Este tipo de trabalho das mulheres libera os homens dos grupos dominantes para se absorver em pensamento abstrato. Quanto mais sucesso as mulheres tem neste tipo de trabalho, mais invisivel este se torna para os homens. 0 cuidado dos corpos desaparece na natureza. Este se torna parte da naturalidade do comportamento altruistico, da ligação maternal, do instinto feminino e por ai afora. Más e preciso definir melhor esta ideia, que implica em varias relacoes complexas e ambivalentes.

Uma ilustracao de tal complexidade encontra-se na questao da maternidade. Quando o "poder natural» da mae e invocado no cuidado de criancas, ou o "instinto feminino" na compreensao das necessidades dos outros, ou o "trabalho de amorn na provisao de atencao, cuidados e arranjos 
domesticos, uma classificacao especifica do ser mulher e enfatizada. Esta classificacao refere-se a uma valorizacao da naturalidade, implicando na adequacao da mulher ao papel de mae, e na nao-adequacao do homem ao papel maternal. A recusa da mulher em assumir o papel daquela que pode consolar um bebe chorando, por exemplo, e a enfase de que qualquer pessoa (independente de genero) pode desenvolver e desempenhar o papel maternal adequadamente, implica em perdas, e em ganhos. Ao desafiar a naturalidade dos papeis femininos as mulheres precisam tanto assumir outros papeis quanto deixar outros (homens e outras mulheres) tomarem seus lugares tradicionais (Silva, 1996). Esta pode ser uma mudanca radical.

A invisibilidade das relacoes tradicionais de genero no cotidiano pode se referir exclusivamente a desempenhos de papeis. Más tais papeis sao reforcados em praticas institucionais e aceitos, ou desafiados, em praticas do dia a dia. Isto pode ser ilustrado com o caso do desenvolvimento de tecnologias do lar. Por exemplo, num estudo que desenvolvi recentemente sobre as tecnologias de cozinha no seculo vinte, eu exploro uma aparente relacao entre construcoes ideologicas da mulher como cozinheira e as inovacoes tecnologicas dos fogoes. As mudancas nos papeis de genero da mulher durante o seculo vinte e a insercao do homem (de alguns homens) na cozinha tem sido acompanhadas por inovacoes tecnologicas onde o conhecimento especializado nao e requerido para operacoes cotidianas de cozimento. Em minha opiniao isto nao revela uma desvalorizacao do papel da mulher, mas sim uma readequacao das inovacoes tecnologicas a expectativas de genero. Em verdade, estas tendencias demonstram que certas politicas e certos interesses de genero, que aparecem inscritos nas tecnologias de cozimento, indicam que as mulheres usuarias tem negociado os seus "scripts" de maneira ativa, redesenhando as fronteiras de genero na cozinha, muitas vezes em conflito com estruturas e normas de vida domestica tradicional (Silva, 2000).

Estudos deste tipo, preocupados em revelar as culturas de genero envolvidas nas praticas tecnologicas, politicas e economicas mais abrangentes, tem sido fundamental para 0 entendimento de exclusoes dos interesses da mulheres.

Da perspectiva dos homens as atividades das mulheres geralmente não sao vistas como parte da cultura humana e da historia porque o seu carater social e muito invisivel dentro da cultura que vivemos.
Entao, se nos partimos do ponto de vista da vida das mulheres (do conhecimento situacionado), podemos perguntar:

- Porque e que se atribui as mulheres este tipo de atividades?

- Quais sao as consequencias para a economia, o estado, a familia, e o sistema educacional, por exemplo, de se atribuir o trabalho do corpo e o trabalho emocional para um grupo na sociedade, e o trabalho da cabeca para outro grupo? 0 corpo fica para as mulheres, a cabeca para os homens?

A exploracao destas questoes pode levar a uma compreensao menos distorcida do mundo das mulheres, do mundo dos homens e das relações entre os dois. Certamente, ao se explorar estas questoes pode-se atingir uma compreensao melhor do que aquela advinda basicamente do trabalho mental abstrato de gerenciamento e administração, tipicamente masculino.

Mas, e claro que a situação da maioria das mulheres não acambarca a situação de todas as mulheres. As vidas de muitas mulheres sao tambem invisiveis para as poucas mulheres que fazem parte do grupo dominante, que tem mulheres cuidando dos seus corpos, dos corpos de seus filhos, e das suas casas, que tem o poder -a vantagem- de ter seu tempo liberado para o trabalho abstrato. No limite, a questao geral e de poder, e de divisao social com exclusao de poder.

E porisso que esta questao e central para a problematica do conhecimento na America Latina. Ela se refere diretamente aos problemas da enorme diferenciação social na regiao. Ela tambem aponta para uma proposta de futuro, em direcao a menores e menos graves divisoes sociais. Como dar conta do ponto de vista dos excluidos?

Eu quero concluir retornando a questao dos pontos de vista. Eu quero enfatizar que na realidade existente nos temos pontos de vista diferentes, ainda quando existe mais igualdade social e economica entre nos. Embora nos não vejamos a realidade de uma mesma maneira, todas nos -0 nos feminista- compartilhamos um interesse em sermos capazes de viver nossas vidas o melhor que pudermos. Isto implica em vivermos nossas vidas livres de intervenções malinformadas e com o melhor conhecimento possivel sobre 0 que tem maior potenciat de nos fazer mais saudaveis, mais 
produtivas, mais felizes e com maior capacidade de contribuir para o bem comum. E claro que eu acho maravilhoso poder viver num momento historico de desafio do conhecimento, onde o feminismo cria tantas inquietações e propicia varios novos caminhos para uma vida melhor se tornar possivel. Ain- da quando as vezes eu lamento que as complexidades e tensoes que as novas buscam acarretam sao peturbadoras, eu sinto-me energizada pelo processo coletivo feminista de desafio aos conhecimentos estabelecidos e com a sustentacao da legitimidade de pontos de vista alternativos. 


\section{NOTAS}

1 A mesa redonda fez parte da ESOCITE 2000, organizada pelo Departamento de Politica Cientifica e Tecnologica, Universidade de Campinas, Brasil, 23-26 de Outubro de 2000. Agradeco a Eulalia Perez Sedeño e as demais participantes pelo estimulo de ideas e comentarios nesta ocasiao.

2 Desde o inicio da minha vida profissional em meados da decada de 1970, eu tenho me engajado com estes assunto, inicialmente no Brasil, depois na Inglaterra e nos Estados Unidos, e consistentemente desde 1992 como parte da comunidade academica britanica nas areas de sociologia e estudos feministas nos campos da tecnologia e da vida domestica.

\section{REFERENCIAS}

Haraway, Donna (1988) "Situated Knowledges: The Science Question in Feminism and the Privilege of Partial Perspectiven, Feminist Studies, 14 (3): 575-99.

Harding, Sandra (1996) "Rethinking Standpoint Epistemology: What is "Strong Objectivity"?» in Evelyn Fox Keller and Helen Longino (eds) Feminism and Science, 0xford: Oxford University Press.

Keller, Evelyn Fox (1992) Secrets of Life, Secrets of Death: Essays on Language, Gender, and Society, New York: Routledge.

Latour, Bruno (1994) Jamais Fomos Modernos. Sao Paulo: Editora 24 Ltd.

Oakley, Ann (2000) Experiments in Knowing. Gender and Method in the Social Sciences. Cambridge: Polity.

Silva, Elizabeth B. (1996) "The transformation of mothering" in E.B.Silva (ed.) Good Enough Mothering? Feminist Perspectives on Lone Motherhood, London: Routledge.

Silva, Elizabeth B. (2000) "The cook, the cooker and the gendering of the kitchen", The Sociological Review, 48 (4): 612-628.

Smith, Dorothy (1988) The Everyday World as Problematic. A feminist sociology, Milton Keynes: The Open University Press.

Smith, Dorothy (1990) The conceptual Practices of Power: a Feminist Sociology of Knowledge, Toronto: University of Toronto Press. 